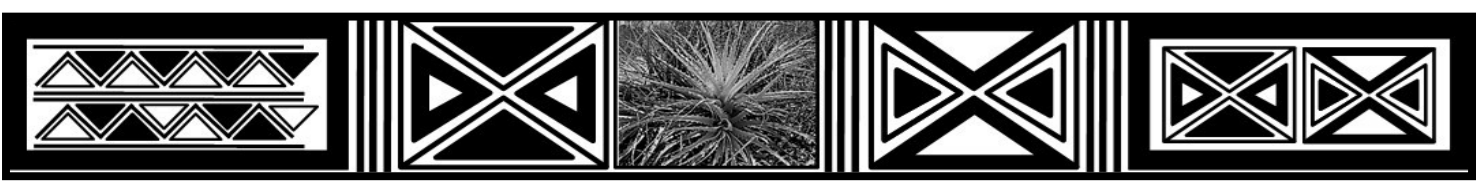

REVISTA MACAMBIRA

LABORATÓRIO DE POLÍTICAS PÚBLICAS, RURALIDADES E DESENVOLVIMENTO TERRITORIAL

Volume 3. Número 2. 2019. ISSN 2594 - 4754

ARTIGO / ARTICLE

DOI: https://doi.org/10.35642/rm.v3i2.269

\title{
PERCEPÇÃO DE AGRICULTORAS E CONSUMIDORES SOBRE ALIMENTOS ORGÂNICOS NO MUNICÍPIO DE SERRINHA-BA
}

\author{
PERCEPTION OF FARMERS AND CONSUMERS ABOUT ORGANIC FOODS IN \\ THE MUNICIPALITY OF SERRINHA-BA
}

\section{Márcio Ricardo Oliveira dos Santos \\ https://orcid.org/0000-0002-9827-8638}

Técnico em Agroecologia. Instituto Federal de Educação, Ciência e Tecnologia

Baiano, Campus Serrinha. E-mail: santosmarcioricardo83@gmail.com

\section{Erasto Viana Silva Gama}

https://orcid.org/0000-0002-7970-4849

Engenheiro Agrônomo, professor no Instituto Federal de Educação, Ciência e Tecnologia Baiano, Campus Serrinha. E-mail: erasto.gama@ifbaiano.edu.br

\section{Carla Teresa dos Santos Marques}

https://orcid.org/0000-0002-7062-0710

Docente no Instituto Federal de Educação, Ciência e Tecnologia Baiano, Campus Serrinha. E-mail: carla.marques@ifbaiano.edu.br

Recebido: 16 de setembro de 2019

Aceito: 03 de março de 2019

RESUMO: A modernização estabelecida pelos países desenvolvidos tem propósitos exclusivos de produção em grande escala, objetivando uma grande quantidade de alimentos no mercado, sem se importar com a qualidade destes alimentos, desconsiderando os parâmetros ambientais, como qualidade de rios e solo, além dos danos diretos à fauna e flora local. Essa realidade, atrelada as investidas da revolução verde, vinha conquistando os olhares da população mundial. Em contrapartida a essa massa, surge o movimento dos alimentos orgânicos, que almeja um olhar mais "sensível" tanto para com o meio ambiente, como para a saúde humana. Com o passar dos anos os alimentos orgânicos ganharam maior força e passaram a impulsionar a agricultura familiar, fortalecendo a renda de famílias. Porém, ainda hoje muitas pessoas ainda optam por consumir alimentos sem a preocupação sobre a origem ou como são produzidos. Deste modo, o presente estudo busca identificar os principais fatores que influenciam na 
produção e comercialização de alimentos orgânicos no município de Serrinha - Ba. Foram entrevistados 12 agricultoras e 94 consumidores, por meio de questionários semiestruturados e elaborados de acordo com a Escala de Likert. No geral, os resultados demonstram que tanto produtores como consumidores, possuem algum conhecimento sobre os alimentos orgânicos, porém a maior parte dos consumidores ainda opta pela estética do alimento no momento da escolha. Este trabalho poderá auxiliar estudos posteriores sobre alimentos orgânicos, que busquem se aprofundar nos meios de influência da sociedade.

PALAVRAS-CHAVE: Agricultoras. Saúde. Feira-livre. Consumidores.

ABSTRACT: The modernization established by developed countries has exclusive purposes of large-scale production, targeting a large amount of food on the market, regardless of the quality of these foods, disregarding environmental parameters, such as the quality of rivers and soil, in addition to direct damage to local fauna and flora. This reality, linked to the onslaught of the green revolution, was winning the eyes of the world population. In contrast to this mass, there is the movement of organic foods, which aims at a more "sensitive" look both for the environment and for human health. Over the years, organic food gained strength and started to boost family farming, strengthening household income. However, even today many people still choose to consume food without worrying about the origin or how they are produced. Thus, the present study seeks to identify the main factors that influence the production and commercialization of organic foods in the municipality of Serrinha - Ba. 12 farmers and 94 consumers were interviewed, using semi-structured questionnaires and prepared according to the Likert Scale. In general, the results show that both producers and consumers have some knowledge about organic foods, but most consumers still choose the aesthetics of the food at the time of choice. This work may help further studies on organic foods, which seek to deepen the means of influence of society.

KEYWORDS: Farmers. Health. Free market. Consumers.

\section{INTRODUÇÃO}

Alimentos orgânicos podem ser definidos como alimentos resultantes do cultivo em sistemas orgânicos de produção. Estes sistemas são desenvolvidos com base em um conjunto de processos e estilos de produção, onde o solo é compreendido como um corpo vivo e altamente dependente da matéria orgânica para responder a demandas de fertilidade. Porém, depois de acontecimentos históricos, a humanidade passou a adotar um sistema de produção convencional, que recorre a pacotes de fertilizantes e inseticidas químicos.

Após a revolução chinesa ocorrida em 1949, foi revelado um novo futuro para os países considerados agrícolas. Uma resposta imediata foi a contrarrevolução capitalista, também conhecida como revolução verde, que veio com o objetivo de impedir a progressão da revolução modernista, transformando o homem em objeto do processo, por meio de uma boa dose de autoritarismo e repressão (PINHEIRO, 2005).

A chegada da revolução verde, trouxe consigo uma malha de agrotóxicos como a única alternativa para combate de algumas "pragas", que naquela época estavam afetando os plantios de café e algodão. No meio desta infestação a frase "Muita saúva e pouca saúde os 
males do Brasil são", passa a dispor de seu verdadeiro entendimento, uma vez que a partir dali começaríamos a combater os efeitos e deixaríamos as causas, como uma forma de estancar o sangue, sem se preocupar com o motivo de tanto sangue (FERRARI, 1985). Com a modernidade da agricultura, os plantios passaram a ser semeados em fileiras como um grande exército verde, a uniformidade era sinônimo de orgulho e o uso de insumos foi levado ao extremo (UZEDA, 2004).

Ainda era tempo de ditadura quando os primeiros agricultores e população passaram a questionar a origem de determinados alimentos, enfim, a população estava começando a perceber o que estava comendo. Porém, como todas as civilizações, mulheres e homens buscavam estruturação e poder, para manter esse poder transformam em crenças aquilo que não compreendem ou temem (PINHEIRO, 2005).

Com isso, o uso de agrotóxicos foi maquiado como crença, proliferando-se por toda a população. A agricultura passou a ser enfraquecida por conta da elevada taxa de êxodo rural e exclusão dos sujeitos do campo, agora tidos como objeto. As empresas transnacionais vieram para tomar posse de grandes extensões de terra para criação de grandes monoculturas, trouxeram consigo ainda as pragas, para melhorar o setor bilionário da comercialização de agrotóxicos, agora elas trazem os transgênicos para compor a produção nacional de alimentos (GUTERRES, 2006).

Quando essa sociedade evolui acumulando saber e riquezas, essas crenças são transformadas em leis escritas para facilitar ainda mais a atuação dos grandes produtores. A sociedade capitalista passa a se firmar no saber para geração de riqueza, a mesma sociedade passa então a atuar sobre homem por meio do trabalho, sobre a terra por meio da exploração e sobre o saber através do incentivo financeiro. No Brasil, infelizmente, o que há é a desvalorização da mão de obra, a exploração da terra e a destruição de costumes e culturas (PINHEIRO, 2005).

No entanto, um movimento vem se mostrando forte contra esse cenário atual, representado como uma verdadeira ditadura verde. O movimento da agricultura orgânica, vem no caminho contrário ao pensamento convencional, pois em primeiro lugar está a qualidade, a origem e principalmente o manuseio dos alimentos antes de chegarem ao consumidor. Ao longo de alguns anos, a produção orgânica vem se intensificado principalmente na área de hortaliças, entretanto, ainda não possuem uma alta taxa demanda por consumidores, comparados aos alimentos convencionais (DUQUE, 2002).

Apesar de toda ferramenta legal, o processo de comercialização se torna muito complexo para um pequeno agricultor, pois exige um conhecimento de administração 
financeira e de produção, em que devesse entender a fundo as demandas consumidoras do mercado, além do planejamento adequado de produção. Em função do abastecimento variável o mercado consumidor de produtos orgânicos se torna instável, uma vez que pequenos e médios agricultores precisam se unir em cooperativas e associações para melhor comercialização de seus produtos (UZEDA, 2004).

Uma saída viável é a comercialização por mercado direto, porém essa alternativa iria requerer uma alta variedade de produtos disponíveis para venda. Este mercado está em formação, com tendência favorável, e dependente da conscientização da população em relação à ingestão de alimentos orgânicos, livres de contaminação por insumos químicos, associado a uma maior regularidade na entrega e viabilidade de preço desses produtos.

Segundo Duque (2002), o maior prejudicado em termos de retorno econômico é o agricultor; atualmente, de todo o valor pago pelo consumidor apenas 30\% desse dinheiro retorna ao agricultor. Com isso o produtor é obrigado a elevar o custo dos alimentos, visando maior obtenção de lucro, no entanto, o preço dos alimentos orgânicos acaba ultrapassando o valor dos alimentos produzidos convencionalmente, o que os torna menos acessíveis para boa parte da população.

A produção por viés orgânico envolve muitos riscos, como a perda da produção por conta de uma praga, já que não é permitido o uso de inseticidas químicos. O processo de comercialização também tem suas dificuldades principalmente nas fases de limpeza, identificação e descrição do modo de produção, além de tentar driblar os grandes atacadistas, cujo critério é baseado em quantidade e preço. Todas essas ações contribuem para alta nos preços dos alimentos Orgânicos (GUTERRES, 2006).

$\mathrm{Na}$ atualidade, a demanda da sociedade por alimentos orgânicos vem se afirmando a cada dia. Nos últimos anos uma infinidade de tecnologias de produção inovadoras vem tomando conta do mercado produtivo de alimentos, e com isso a população passou a assumir novos estilos de vida, com preocupações em relação à saúde e meio ambiente. Este panorama justifica a iniciativa de produtores orgânicos em aumentar seu mercado consumidor, para atender a demanda crescente de alimentos produzidos sem uso de agrotóxicos (PINHEIRO,2005).

De acordo com o levantamento realizado pelo Idec, no Brasil existem 792 feiras ou agroecológicas, 200 destas são no Nordeste e 46 na Bahia (IDEC, 2019). Dentre estas feiras, o Território do Sisal, além de Serrinha, são listadas no mapa do Idec as feiras agroecológicas e orgânicas de Araci e Barrocas e Quijingue. 
Desse modo, o presente estudo busca identificar os principais fatores que influenciam na produção e comercialização de alimentos orgânicos no município de Serrinha $-\mathrm{Ba}$.

\section{MATERIAL E MÉTODOS}

A pesquisa foi realizada com agricultoras familiares e consumidores residentes na cidade de Serrinha. Para identificação dos possíveis fatores que influenciam na produção e comercialização de alimentos orgânicos, optou-se por aplicação de três tipos de questionários de natureza semiestruturada.

O primeiro questionário é o geral, aplicado a todos os entrevistados, tanto produtores quanto consumidores. Neste questionário foram abordados dados gerais como gênero, residência, idade, respectivo conhecimento sobre alimento orgânico e agrotóxico, além do conceito de saúde e alimento, com o intuito de caracterizar o público da pesquisa. No total foram entrevistadas 106 pessoas, já incluindo agricultores e consumidores.

O segundo e terceiro questionários foram montados utilizando a escala de Likert (ESCALA DE LIKERT, 2017), que por sua vez ofereceu ao trabalho uma melhor constatação do grau de conhecimento e o nível de concordância ou não dos entrevistados em relação ao tema comercialização e produção orgânica. A escala é composta por afirmativas feitas, em que o entrevistado deve optar por concordar ou não com estas afirmativas, levando em consideração o grau de intensidade de sua resposta, podendo também concordar totalmente e discordar totalmente, ou simplesmente ser neutro em relação a afirmação.

O segundo questionário foi direcionado aos agricultores. Foram entrevistadas 12 agricultoras familiares. No questionário se encontravam afirmações sobre a forma de produção e os benefícios dos alimentos orgânicos, como segue: 1) A única maneira de se produzir bem é utilizando agrotóxicos; 2) A produção de alimentos orgânicos é bem aceita pela maioria da população; 3) Um dos maiores desafios da produção orgânica é conhecer cada cultura que irá ser produzida; 4) O valor elevado dos alimentos orgânicos é resultado principalmente de um difícil manejo; 5) A não utilização de agrotóxicos melhoram a qualidade do alimento, além de não comprometer o meio ambiente; 6) A utilização de agrotóxicos facilita o manejo de pragas e doenças, além de não fazer mal à saúde humana; 7) Hoje no mercado há uma baixa oferta de alimentos, em relação à demanda da população; 8) Um dos principais fatores que influenciam na decisão dos consumidores na hora da compra 
é o preço; 9) Os fatores que influenciam no preço dos alimentos orgânicos estão ligeiramente relacionados à concorrência de mercado; 10) A produção dos produtos orgânicos se mostra, além do simples cultivo, sem agrotóxicos.

Já o terceiro questionário foi direcionado aos consumidores, nele constavam afirmações sobre a qualidade dos alimentos orgânicos, além de aspectos relacionados à decisão entre alimentos orgânicos ou convencionais. O questionário foi composto das seguintes afirmações: 1) O alimento orgânico é produzido sem o uso de agrotóxicos, o que eleva sua qualidade; 2) O uso de agrotóxicos na produção de alimentos, pode afetar seriamente a saúde humana; 3) Aqueles alimentos cuja a aparência é mais agradável, possui maior confiabilidade em questões de saúde; 4) O preço dos alimentos influencia seriamente na hora da decisão de que alimento levar; 5) A qualidade do alimento está diretamente ligada à forma de produção; 6) $\mathrm{O}$ consumidor está sempre em busca do melhor alimento, independente do preço; 7) A escolha dos alimentos está seriamente ligada à aparência; 8) O alimentos de maior tamanho são considerados mais saudáveis; 9) No mercado atual, há uma grande diversidade de alimentos orgânicos para comercialização; 10) Os alimentos não fazem mal a saúde, independentemente de sua forma de produção.

Participaram da pesquisa 94 consumidores, dentre estes, 39 na feira com média de idade referente a 36 anos, 45 na rede de supermercados com média de idade igual a 37 anos e 10 consumidores livres presentes nos arredores do comércio com média de idade igual a 40 anos.

Após a realização das entrevistas, os dados foram tabulados e analisados com auxílio de planilhas e gráficos do software livre da plataforma BR OFFICE ${ }^{\circledR}$.

\section{RESULTADOS}

A análise dos resultados foi dividida em três partes para melhor entendimento. A primeira trata-se da análise e caracterização do público pesquisado e a sua compreensão sobre saúde e doença; a segunda e a terceira referem-se à análise das respostas obtidas através da aplicação dos questionários às agricultoras e aos consumidores, respectivamente.

\section{Caracterização dos entrevistados}

$\mathrm{Na}$ tabela 1, encontra-se a síntese dos dados de caracterização das agricultoras e consumidores entrevistados, os quais apresentaram média de 38 anos. Já em relação ao gênero, percebemos que existe uma extrema maioria feminina, principalmente dentre as produtoras. Ainda na caracterização dos entrevistados, a coleta de dados mostra uma maioria 
residente em zona urbana, representada por $77 \%$ dos entrevistados, enquanto apenas $33 \%$ reside em zona rural.

Quando relacionado os conceitos de saúde e alimento, com a definição adotada pelos entrevistados, observamos que a maior parte dos entrevistados tem uma boa definição sobre saúde e alimentação; o que deixou uma grande dúvida, já que eles estão informados sobre o que é, ou pelo menos já ouviram falar em alimentos orgânicos. Qual seria o motivo da procura reduzida na feira orgânica, quando comparada a dos supermercados da cidade?

A análise de informação das agricultoras e consumidores, tendo em vista que $96 \%$ dos entrevistados já ouviram falar sobre alimento orgânico e/ou agrotóxico, nos levou a uma possível razão para isso, que seria o fato de mesmo tendo acesso a informações sobre alimentos orgânicos, embora essas informações não sejam tão completas ou claras o suficiente para entendimento da população. Logo essa dúvida seria esclarecida após análise dos dois questionários restantes.

TABELA 1. Caracterização das produtoras e dos consumidores (as) de produtos orgânicos entrevistados na feira livre e comercio de Serrinha - BA. Fonte: Pesquisa de Campo, 2018.

\begin{tabular}{|c|c|c|c|c|}
\hline \multirow{2}{*}{\multicolumn{2}{|c|}{$\begin{array}{c}\text { CARACTERÍSTICAS } \\
\text { MÉDIA DE IDADE (ANOS) }\end{array}$}} & \multirow{3}{*}{$\begin{array}{c}\text { PROD. } \\
43 \\
0\end{array}$} & \multirow{3}{*}{$\begin{array}{c}\text { CONS. } \\
37 \\
15\end{array}$} & \multirow{3}{*}{$\begin{array}{c}\text { GERAL } \\
38 \\
13\end{array}$} \\
\hline & & & & \\
\hline \multirow{2}{*}{ GENÊRO } & $\% \mathrm{M}$ & & & \\
\hline & $\% \mathrm{~F}$ & 100 & 85 & 87 \\
\hline \multirow[t]{2}{*}{ RESIDÊNCIA } & $\%$ RURAL & 100 & 14 & 23 \\
\hline & $\%$ URBANA & 0 & 86 & 77 \\
\hline \multirow{2}{*}{$\begin{array}{c}\text { JÁ OUVIU } \\
\text { FALAR EM } \\
\text { ALIMENTO } \\
\text { ORGÂNICO? }\end{array}$} & $\%$ SIM & 100 & 96 & 96 \\
\hline & $\% \mathrm{NÃO}$ & 0 & 4 & 4 \\
\hline \multirow{2}{*}{$\begin{array}{c}\text { JÁ OUVIU } \\
\text { FALAR EM } \\
\text { AGROTÓXICO? }\end{array}$} & $\%$ SIM & 100 & 96 & 96 \\
\hline & $\% \mathrm{NA \tilde {O }}$ & 0 & 4 & 4 \\
\hline \multirow[t]{3}{*}{ ALIMENTO É? } & $\begin{array}{c}\% \\
\text { COMBUSTÍVEL }\end{array}$ & 25 & 28 & 28 \\
\hline & $\begin{array}{l}\% \text { FONTE DE } \\
\text { SAÚDE }\end{array}$ & 70 & 56 & 54 \\
\hline & $\begin{array}{l}\% \text { SACIAR A } \\
\text { FOME }\end{array}$ & 5 & 16 & 18 \\
\hline \multirow[t]{2}{*}{ SAÚDE É? } & $\begin{array}{l}\% \text { AUSENCIA } \\
\text { DE DOENÇA }\end{array}$ & 16 & 41 & 38 \\
\hline & $\%$ BEM-ESTAR & 84 & 59 & 62 \\
\hline
\end{tabular}

\section{Percepção das agricultoras}

Para análise dos questionários referente às agricultoras, foram desenvolvidas figuras que retratam o percentual de concordância dos entrevistados com as afirmações presentes no questionário. 
Quando as agricultoras foram interpoladas com a afirmação de que a produção de alimentos orgânicos é bem aceita pela maioria da população, 92\% das entrevistadas concordam e 8\% discordam (FIGURA 1).

FIGURA 1. Nível de concordância das agricultoras entrevistadas na feira livre de SerrinhaBA quando interpoladas pela afirmação: a produção de alimentos orgânicos é bem aceita pela maioria da população. Fonte: Pesquisa de campo, 2018.

\section{2}

\section{\begin{tabular}{llllll}
\hline $0 \%$ & $20 \%$ & $40 \%$ & $60 \%$ & $80 \%$ & $100 \%$
\end{tabular} \\ $\backsim$ CONCORDO TOTALMENTE $₫$ CONCORDO $₫$ NEUTRO $₫$ DISCORDO $₫$ DISCORDO TOTALMENTE}

Em relação ao preço elevado dos alimentos orgânicos, 100\% das entrevistadas concordaram que é resultado principalmente de um difícil manejo (FIGURA 2).

Com relação à oferta de produtos orgânicos, 75\% das entrevistadas concordam que hoje no mercado há uma baixa oferta de alimentos orgânicos, em relação à demanda da população (FIGURA 2), no entanto, esse parâmetro se deve, principalmente, à insegurança das agricultoras em elevar sua oferta de alimentos e não conseguir comercializar todo estoque produzido.

Em relação à decisão de compra, 83\% das agricultoras concordam que o preço é um dos principais fatores (FIGURA 2). Acerca dos fatores que influenciam no preço dos produtos orgânicos, $58 \%$ das entrevistadas concordam que estes fatores estão ligeiramente relacionados à concorrência de mercado (FIGURA 2).

$\mathrm{Na}$ Figura 3, observa-se que na visão das agricultoras, quando interpoladas com a afirmação de que a produção de alimentos orgânicos é bem aceita pela maioria da população, $92 \%$ das entrevistadas concordaram, isso pelo fato de existir uma boa procura, segundo relatos das mesmas, entretanto, essa procura ainda é inferior se comparada à procura por alimentos convencionais. 
FIGURA 2. Opinião das agricultoras em relação aos fatores que determinam o preço dos alimentos orgânicos. Fonte: Pesquisa de campo, 2018.

Os fatores que influenciam no preço dos alimentos orgânicos estão ligeiramente relacionados à concorrência de mercado.

Um dos principais fatores que influenciam na decisão dos consumidores na hora da compra é o preço.

Hoje no mercado há uma baixa oferta de alimentos, em relação à demanda da população.

O valor elevado dos alimentos orgânicos é resultado principalmente de um difícil manejo.

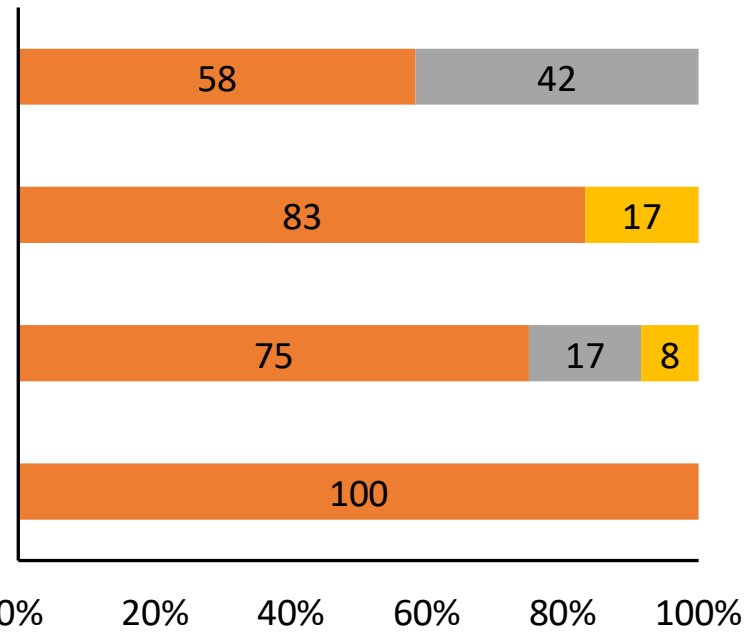

C/TOTALMENTE $\square$ CONCORDO NEUTRO DISCORDO D/TOTALMENTE

FIGURA 3. Nível de aceitação da população em relação a produção orgânica. Fonte: Pesquisa de campo, 2018.

\section{A produção de alimentos orgânicos é bem aceita pela maioria da população.}

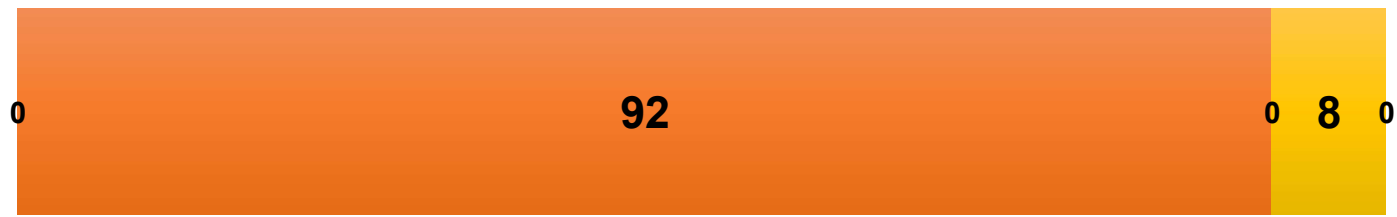

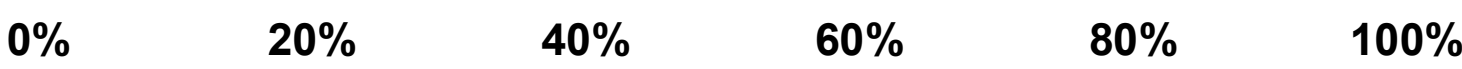 \\ $\backsim$ CONCORDO TOTALMENTE $₫$ CONCORDO $\approx$ NEUTRO $\approx$ DISCORDO $\approx$ DISCORDO TOTALMENTE}

A Figura 4, exibe a posição adotada pelas produtoras em relação às afirmações referente a forma de produção orgânica. Percebe-se que as agricultoras possuem um entendimento sobre as formas de produção orgânica, uma vez que todas discordaram das afirmações que defendiam o uso de agrotóxico para uma produção mais eficiente. Todas as agricultoras afirmam que a produção orgânica é bem mais que uma simples forma de produzir bem, sem a utilização de agrotóxicos.

Em diálogo com elas, muitas relataram que a produção orgânica deve ser vista como um estilo de vida a ser adotado. E que uma das maiores dificuldades enfrentadas é conhecer cada cultura que irá ser produzida. 
FIGURA 4. Opinião das agricultoras em relação a forma de produção dos alimentos orgânicos. Fonte: Pesquisa de campo, 2018.

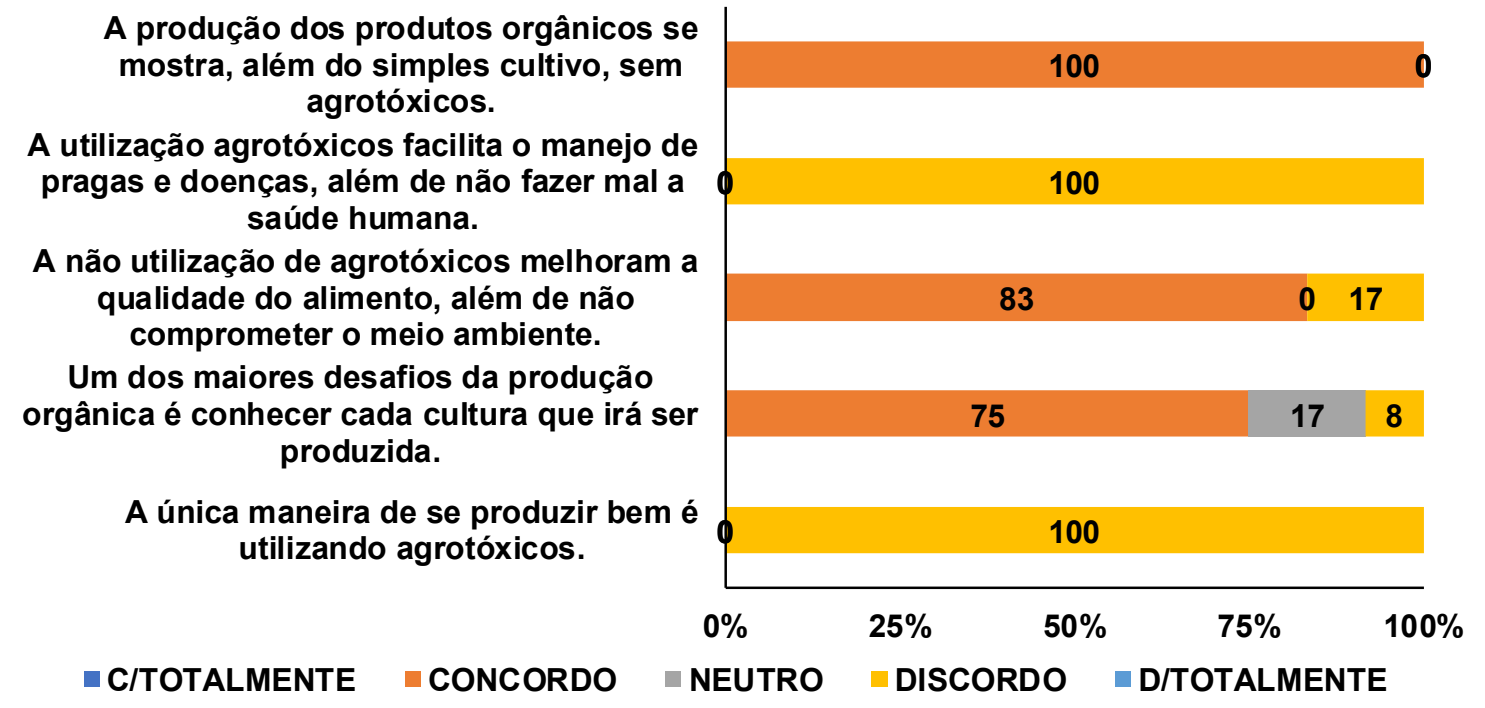

\section{Percepção dos consumidores}

Considerando os 94 consumidores entrevistados, seus posicionamentos frente a afirmação de que a produção sem agrotóxico eleva a qualidade dos alimentos, 29,8\% dos consumidores concordaram totalmente que o alimento produzido sem uso de agrotóxico tem sua qualidade elevada, enquanto $52,1 \%$ apenas concordou e outros, $1,1 \%$, 9,6\% e 7,4\% respectivamente ficaram neutros, discordaram e discordaram totalmente (FIGURA 5).

FIGURA 5. Opinião dos consumidores sobre a forma de produção orgânica. Fonte: Pesquisa de campo, 2018.

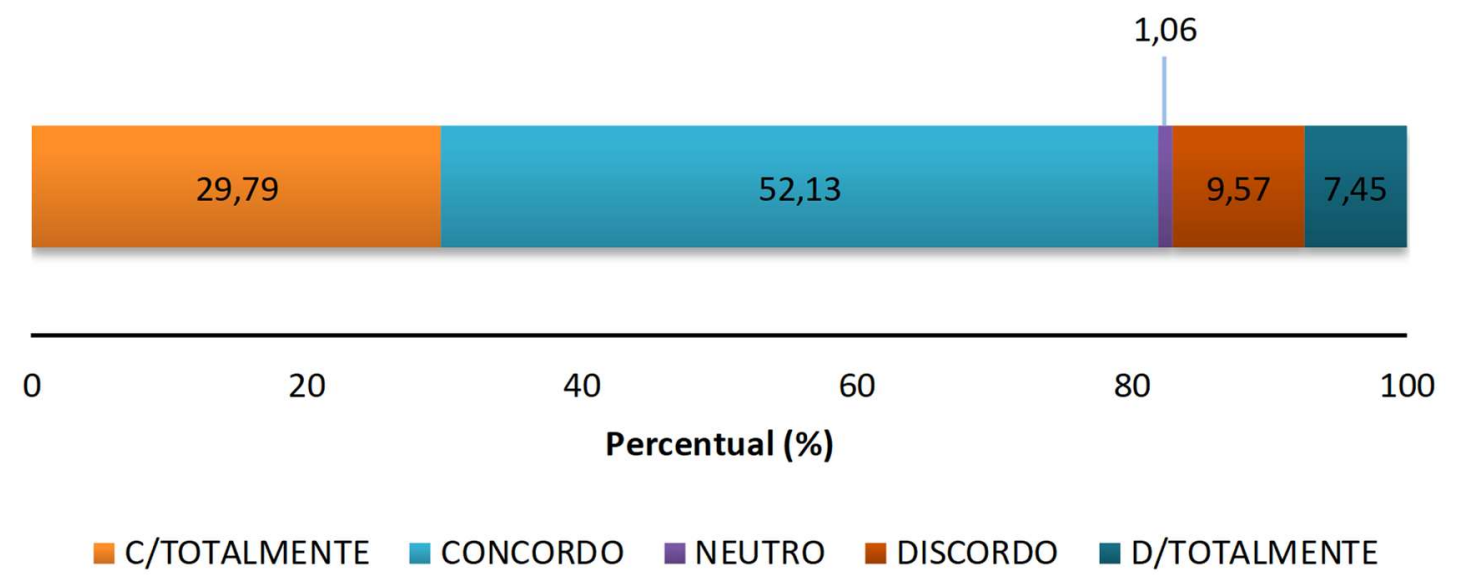

Na segunda afirmação houve um equilíbrio maior, onde 21,3\% dos consumidores concordaram totalmente que o uso de agrotóxicos pode afetar seriamente na saúde humana, 
enquanto 30,9\% apenas concordou, 16\% ficaram neutros, 26,6\% discordaram e 5,3\% discordaram totalmente (FIGURA 6).

FIGURA 6. Opinião dos consumidores sobre a utilização de agrotóxicos na produção de alimentos. Fonte: Pesquisa de campo, 2018.

21

20
31

40

Percentual (\%)
16

27

80

100

\section{C/TOTALMENTE $\square$ CONCORDO $\square$ NEUTRO $\square$ DISCORDO $\square$ D/TOTALMENTE}

$\mathrm{Na}$ quarta afirmação diz que o preço dos alimentos influenciam muito na hora da compra, cerca de $52 \%$ dos consumidores concordaram totalmente, 5\% apenas concordou, $22,3 \%$ permaneceram neutros quanto à resposta, alegando que depende da ocasião, 4,3\% discordaram e 16\% discordaram totalmente, segundo eles, sempre optam pelos mais saudáveis independente do preço (FIGURA 7).

FIGURA 7. Visão dos consumidores sobre a influência do preço na decisão de compra dos alimentos orgânicos. Fonte: Pesquisa de campo, 2018.

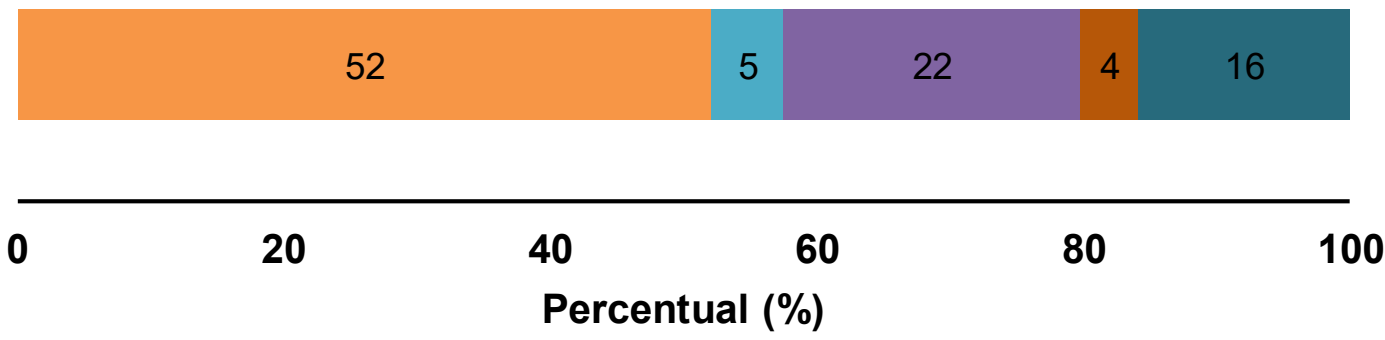

\section{$\because$ C/TOTALMENTE $\backsim$ CONCORDO $\backsim$ NEUTRO $\backsim$ DISCORDO $\backsim$ D/TOTALMENTE}

As afirmações 5 e 10 foram analisadas juntas pois são antagônicas, ambas relatam sobre a forma de produção dos alimentos. Ao analisarmos os dados vemos um choque de informações, que podem indicar um possível falta de informação dos consumidores, uma vez que $70 \%$ afirma que a qualidade do alimento está diretamente ligada a forma em que ele 
e produzido, enquanto outros 50\% afirmam que alimento não faz mal, independente da forma de produção (FIGURA 8).

FIGURA 8. Opinião dos consumidores quando questionados sobre a qualidade dos alimentos aliada a forma de produção. Fonte: Pesquisa de campo, 2018.

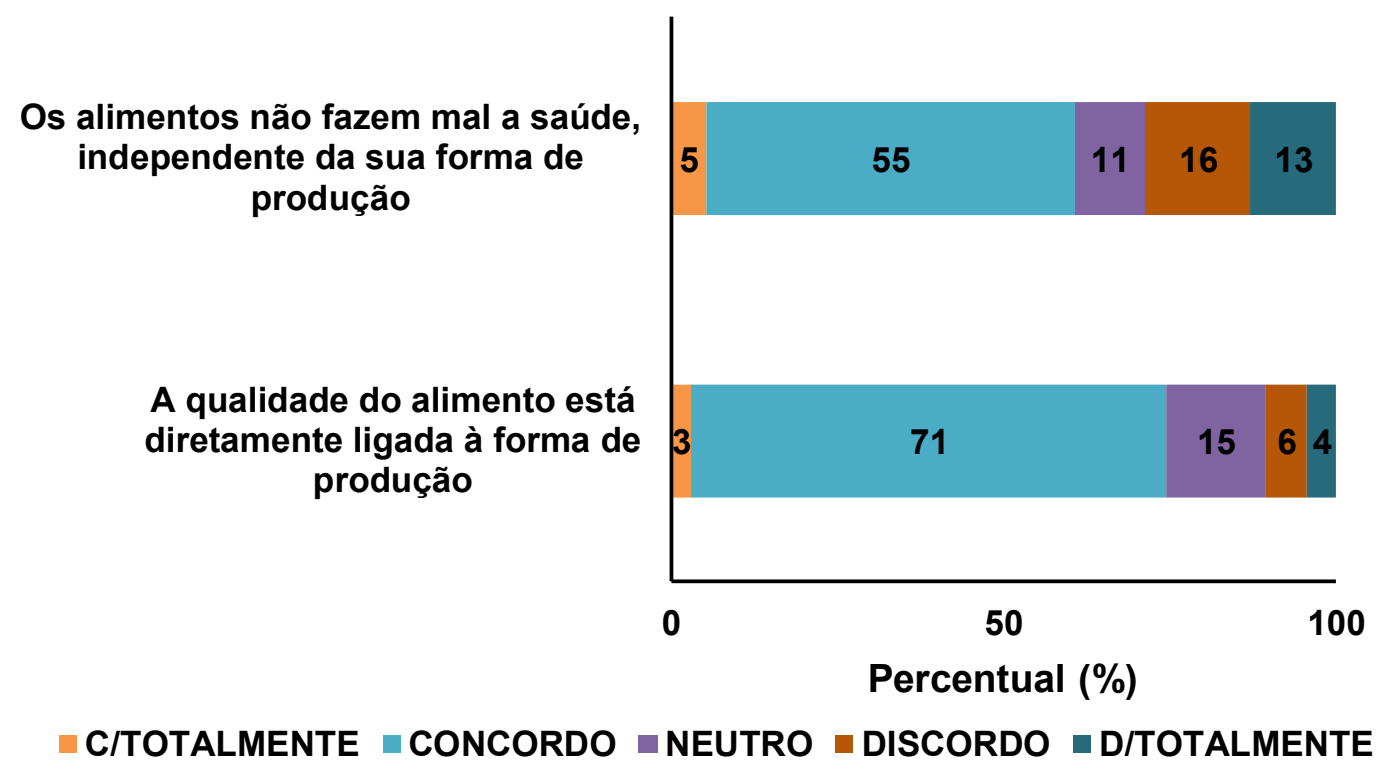

As afirmações 7, 8 e 3 também se relacionam entre si, pois tratam a influência da aparência do alimento na hora da compra. Nesse quesito, 52\% dos consumidores concordaram que a aparência influência muito na hora da compra, porém $36 \%$ desses mesmos consumidores sugerem na afirmativa 3 que os alimentos com melhor aparência são os mais saudáveis (FIGURA 9).

FIGURA 9. Influência da aparência dos alimentos no momento da compra. Fonte: Pesquisa de campo, 2018.

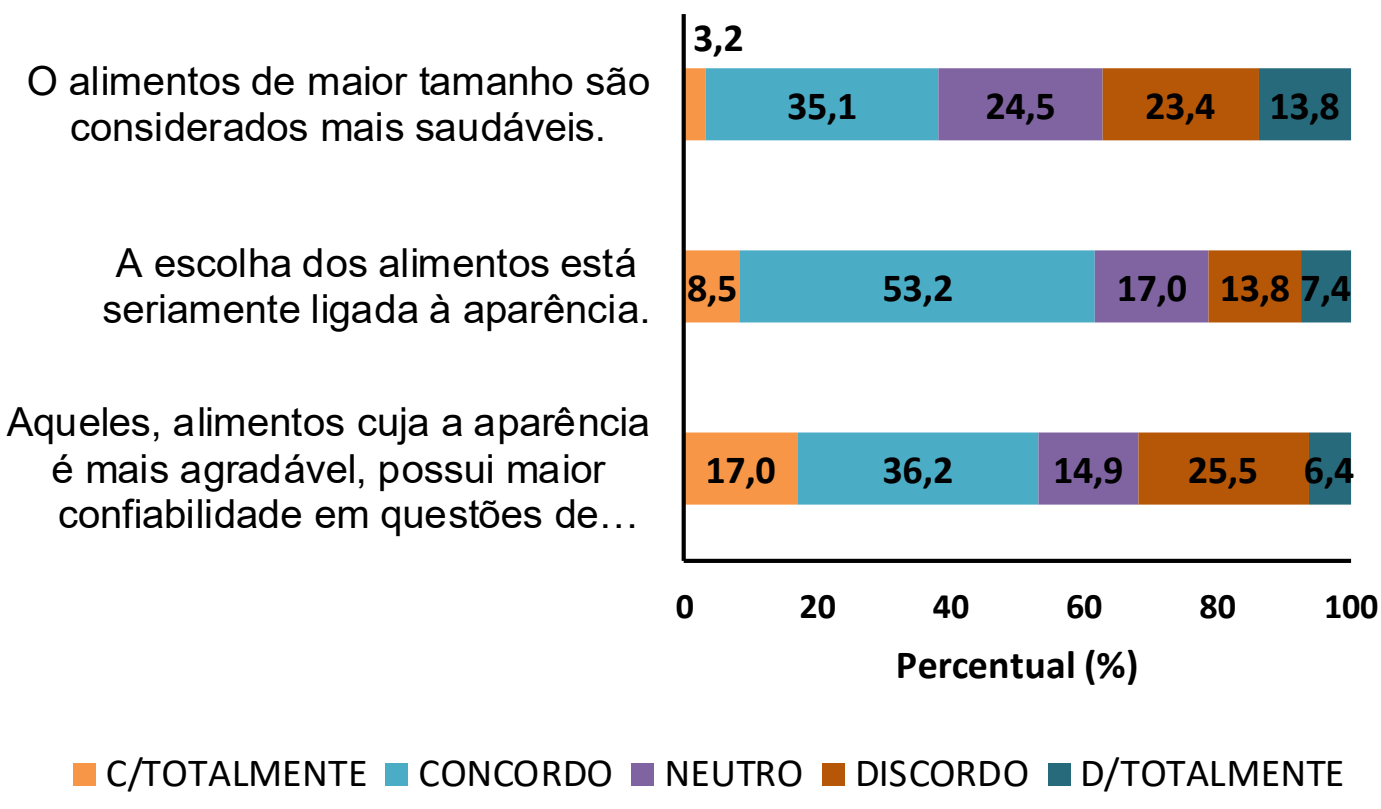


A última questão abordada é a afirmativa 9, que diz: no mercado atual há uma grande variedade de alimentos orgânicos. Com relação a isso, 35\% dos consumidores concordaram totalmente com esta afirmação, o que nos leva a pensar que eles sabiam que existem alimentos orgânicos próximos a eles em grande variedade. Outros $24 \%$ apenas concordaram, pois dizem não saber ao certo a origem real dos alimentos (FIGURA 10). O que nos remete novamente, a análise das respostas das agricultoras, alegando que os consumidores não sabem muitas vezes identificar um alimento orgânico e não procuram saber sua procedência.

FIGURA 10. Opinião dos consumidores sobre a disponibilidade de uma vasta variedade de alimentos orgânicos no mercado. Fonte: Pesquisa de campo, 2018.

\begin{tabular}{llll|l}
35 & 24 & 17 & 16 & 7
\end{tabular}

\begin{tabular}{llllll}
\hline 0 & 20 & 40 & 60 & 80 & 100 \\
& & Percentual $(\%)$ & &
\end{tabular}

\section{C/TOTALMENTE $\backsim$ CONCORDO $\backsim$ NEUTRO $\backsim$ DISCORDO $\backsim$ D/TOTALMENTE}

\section{DISCUSSÃO}

Com relação ao conhecimento dos entrevistados acerca dos alimentos orgânicos e agrotóxicos, percebe-se que cerca de $96 \%$ já ouviram falar em alimentos orgânicos e/ou agrotóxicos. Desta forma pode ser observado que a maioria dos entrevistados tem acesso as notícias, sejam a partir dos meios de comunicação ou mesmo outras fontes.

É perceptível que o conceito de alimento orgânico já está disseminado na sociedade brasileira e é de conhecimento da população serrinhense, no entanto, não é possível afirmar se as informações que a população tem acesso provém de fontes confiáveis e/ou idôneas.

Dados semelhantes foram encontrados por Monteiro et al. (2003), numa pesquisa onde os autores investigaram a percepção dos consumidores sobre os atributos dos alimentos orgânicos na cidade de São Paulo. Monteiro et al. (2003), verificaram que cerca de $72 \%$ dos entrevistados se mostraram conhecedores do conceito de alimento orgânico principalmente vinculado a notícias dispostas nas redes de comunicação, enquanto que neste estudo foram todos os consumidores entrevistados. 
Pode-se perceber ainda, com os resultados que a compreensão sobre a definição de alimento e saúde, não se estende entre toda a população, apenas uma maioria simples $(54 \%)$ definiu alimento como fonte de saúde e saúde como bem estar (62\%). Com relação à quantidade de respostas, esta quantidade é relativamente baixa pois $28 \%$ e $18 \%$ dos entrevistados não definiram alimento como fonte de saúde, mas definiram como combustível para o corpo e algo para saciar a fome respectivamente, na definição de saúde os outros 38\%, compreendem saúde apenas como ausência de doença. Neste sentido, é possível que o “conhecimento" sobre o assunto, está vinculado a informações divulgadas através de redes de integração social.

Em diferença Monteiro et al. (2003), que levou em consideração apenas a visão dos consumidores, o presente estudo considerou também a percepção dos agricultores junto às dos consumidores, uma vez que é pertinente saber o ponto de vista daqueles que produzem, em relação ao alimento produzido e a comercializado.

Considerando as características dos produtos de acordo com a percepção dos consumidores, a influência da aparência dos alimentos na hora da compra é um parâmetro importante a se destacar, uma vez que o mesmo divide opiniões dentre os consumidores. No estudo desenvolvido por Monteiro et al. (2003), os pesquisadores perceberam que o produtor não acredita ser capaz de diferenciar um alimento orgânico de um alimento convencional, muito em razão de associarem muito a aparência com o produto preferível, mesmo existindo alguns consumidores capazes de fazer essa distinção, principalmente entre aqueles cujo convívio com o alimento é maior.

A percepção realizada por Monteiro et al. (2003), é confirmada com este trabalho, a partir da análise de nível de concordância dos consumidores com as afirmações sobre esse tema, nas afirmativas 3, 7 e 8 que fazem referência à aparência dos alimentos.

Fazendo análise no âmbito da saúde, $28 \%$ e 52\% afirmaram que concordam e concordam totalmente, respectivamente, que os alimentos orgânicos não trazem malefícios à saúde. Estes dados demostram uma boa visão dos agricultores em relação aos alimentos orgânicos, porém essa percepção deve ser considerada, em conjunto ao conceito de saúde, em que de acordo com 59\% dos consumidores saúde é a sensação de bem-estar.

Essa compreensão indica que os alimentos orgânicos podem representar uma fonte de saúde para o corpo e para a mente, e o conhecimento dos consumidores sobre estarem consumindo algo de procedência confiável. 
Monteiro et al. (2003), perceberam situação semelhante em São Paulo e afirma que esse é o aspecto mais claro da sua pesquisa onde uma maioria extrema concordou que os alimentos orgânicos não fazem mal à saúde.

Em relação a acesso e disponibilidade dos alimentos orgânicos é observa-se que os consumidores e produtores dividem opiniões interessantes. $53 \%$ dos consumidores concordaram totalmente que o preço influência na hora da compra e 59\% concordam que existe uma grande variedade de alimentos orgânicos para comercialização. Já as agricultoras 10 das 12 entrevistadas concordaram que hoje no mercado existe uma baixa oferta de alimentos orgânicos no mercado, o que reflete também no preço.

As agricultoras entrevistadas possuem uma boa formação relacionada à produção dos alimentos orgânicos. Esta afirmativa é verificada na análise dos dados quando 10 das 12 agricultoras afirmam que a não utilização de agrotóxico melhoram a qualidade do alimento, além de não comprometer a saúde humana e a sustentabilidade ambiental.

Porém, quando se trata dos desafios da produção orgânica 10 das 12 agricultoras também concordam que o mais difícil é conhecer cada cultura a ser produzida, por esse motivo também afirmam que a alta dos preços dos alimentos orgânicos se deve a um difícil manejo.

Quando ao fim provocadas sobre a produção orgânica, todas as 12 agricultoras, responderam que produção orgânica é algo muito além da simples forma de produzir de o uso de insumos ou aditivos químicos, afirmando que produzir organicamente também é um estilo de vida que deve ser adotado e executado com amor, para que seja feito da melhor forma possível.

\section{CONSIDERAÇÕES}

Com a realização do presente trabalho é possível considerar finalmente que:

1. As agricultoras e consumidores do município de Serrinha - BA, possuem uma formação relevante quanto ao tema alimento orgânico e suas características;

2. Existem lacunas a serem fechadas, principalmente na concepção dos consumidores, uma vez que os mesmos afirmam conhecer os benefícios dos alimentos orgânicos, no entanto ainda optam pela estética do alimento no momento da escolha;

3. As agricultoras ainda sentem receio de perder a competitividade para alimentos convencionais, uma vez que poucos consumidores se preocupam mesmo em saber a procedência dos alimentos que irá consumir; 
4. Os consumidores possuem um nível de informação, porém, ainda é necessário saber a procedência dessa informação, pois muitos consumidores que se caracterizam como informados não possui à disposição uma rede informacional confiável o suficiente;

5. Este trabalho poderá auxiliar estudos posteriores sobre alimentos orgânicos, que busquem se aprofundar nos meios de influência da sociedade.

\section{REFERÊNCIAS}

DUQUE, G. Agricultura familiar meio ambiente e desenvolvimento: ensaios e pesquisa em sociologia rural. João Pessoa, Paraíba, Brasil: Editora UFPB, 2002. 237 p.

ESCALA DE LIKERT: o quê é como utilizá-la. Disponível em: < https://www.netquest.com/blog/br/escala-likert>. Acesso em: 28 out. 2017.

FERRARI, A. Agrotóxicos: A praga da dominação. Rio Grande do sul, Brasil: Editora Mercado Aberto, 1985. 87 p.

GUTERRES, I. Agroecologia militante: Contribuições de Ênio Guterres. São Paulo, São Paulo, Brasil: Editora Expressão Popular, 2006.179 p.

IDEC - INSTITUTO BRASILEIRO DE DEFESA DO CONSUMIDOR. Mapa de feiras orgânicas. Feiras orgânicas. 2019. Disponível em: <https://feirasorganicas.org.br/>. Acesso em: 23 nov. 2019.

PINHEIRO, S. A máfia dos alimentos no Brasil. Federação dos Estudantes de Agronomia do Brasil - FEAB. 2005. 280 p.

MONTEIRO, M. N. C.; SALGUEIRO, M.; COSTA, R. T.; GONZALEZ, R. B. Os alimentos orgânicos e a percepção de seus atributos por parte dos consumidores. In.: VII Semana Acadêmica de Administração: Pesquisa Quantitativa Marketing - VII SEMED, 2003.

UZEDA, M.C. O desafio da agricultura sustentável: Alternativas viáveis para o Sul da Bahia. Ilhéus, Bahia, Brasil: Editora UESC, 2004. 131 p. 